Supplementary Information for

\title{
Contrasting Thermoelectric Transport Properties of $N$-type PbS Induced by Adding Ni and $\mathrm{Zn}$
}

Zhenghao Hou ${ }^{1}$, Tao Hong ${ }^{1}$, Dongyang Wang ${ }^{1}$, Xiang Gao ${ }^{3}$, Yuting Qiu*2, Li-Dong Zhao**1

1. School of Materials Science and Engineering, Beihang University, Beijing 100191, China

2. Beihang School, Beihang University, Beijing 100191, China

3. Center for High Pressure Science and Technology Advanced Research, Beijing 100094, China

*Corresponding to: qyt2014@buaa.edu.cn; zhaolidong@buaa.edu.cn

\section{Contents}

1. Experimental section

2. The thermoelectric transport properties of $n$-type $\mathrm{PbS}$ by adding $\mathrm{Ni}$ atoms

3. The thermoelectric transport properties of $n$-type $\mathrm{PbS}$ by adding $\mathrm{Zn}$ atoms

4. References 


\section{Experimental section}

Synthesis. High purity elements $\mathrm{Pb}$ (99.99 \%), S (99.99 \%), In (99.99 \%), Ni $(99.99 \%)$ and $\mathrm{Zn}(99.99 \%)$ were weighed in stoichiometric ratios as $\mathrm{Pb}_{0.995} \operatorname{In}_{0.005} \mathrm{~S}+\mathrm{x} \%$ $\mathrm{Ni} / \mathrm{Zn}(\mathrm{x}=0,2,4,5,6)$. Then the weighted elements were encapsulated in a quartz tube under a pressure of less than $\sim 10^{-4}$ Torr. The quartz tubes were slowly heated up to $723 \mathrm{~K}$ over $12 \mathrm{~h}$, then elevated to $1423 \mathrm{~K}$ over 7 hours, kept at $1423 \mathrm{~K}$ for $6 \mathrm{~h}$, and finally naturally cooling. The obtained ingots were ground into powder and densified by spark plasma sintering (SPS-211LX). First, the temperature of the equipment is heated from room temperature to $923 \mathrm{~K}$ for $10 \mathrm{~min}$ under $50 \mathrm{MPa}$. When the maximum temperature is reached, the sample is fully sintered for $5 \mathrm{~min}$ at maximum temperature. Finally, the system is naturally cooled to room temperature. The SPSed pellets were ground into powder and characterized by XRD.

Electrical and thermal transport measurements. The acquired bulk samples were cut and polished into a cuboid shape with $10 \mathrm{~mm} \times 3 \mathrm{~mm} \times 3 \mathrm{~mm}$ to measure the $\sigma$ and $S$ using CTA equipment (Cryoall, China). For the purpose of preventing the samples from volatilizing and protecting the experimental instrument, the surface of the samples was coated by a thin layer of boron nitride. The typical cylindrical wafer materials with $\Phi \sim 8 \mathrm{~mm}$ and $\sim 1 \mathrm{~mm}$ thickness were employed in the thermal diffusivity $(D)$ measurement by using Netzsch LFA457 instrument. The total thermal conductivity $\left(\kappa_{\mathrm{tot}}\right)$ was calculated by $\kappa_{\mathrm{tot}}=D C_{p} \rho$, in which the heat capacity $\left(C_{p}\right)$ was calculated based on Dulong-Petit law with taking into account of the Debye temperature of $199 \mathrm{~K}$ for $\mathrm{PbS}, 1,2$ and the sample density $(\rho)$ was obtained by using dimensions and mass of sample and confirmed by Archimedes method. The densities of all samples are all around $7.2 \mathrm{~g} / \mathrm{cm}^{3}$. The uncertainty of $\sigma, S$ and $\kappa_{\text {tot }}$ are $5 \%, 5 \%$, $8 \%$, respectively. The overall uncertainty estimated for $Z T$ are less than $20 \%$. The Hall coefficient $\left(R_{\mathrm{H}}\right)$ was obtained by Lake Shore 8400 system with the size of $8 \mathrm{~mm}$ $\times 8 \mathrm{~mm}$ and 1-2 mm thickness under a constant magnetic field. The carrier concentration $\left(n_{\mathrm{H}}\right)$ was determined by the equation of $n_{\mathrm{H}}=1 /\left(e R_{\mathrm{H}}\right)$, where $e$ expresses electron charge. The carrier mobility $\left(\mu_{\mathrm{H}}\right)$ was obtained by $\mu_{\mathrm{H}}=\sigma R_{\mathrm{H}}$. The $P F_{\text {ave }}$ and $Z T_{\text {ave }}$ were calculated by Equation (1)-(2) and the $T_{\mathrm{h}}$ and $T_{\mathrm{c}}$ are the temperatures of the 
hot and cold ends.

$$
\begin{aligned}
& P F_{\text {ave }}=\frac{1}{T_{h}-T_{c}} \int_{T_{c}}^{T_{h}} P F d T \\
& Z T_{\text {ave }}=\frac{1}{T_{h}-T_{c}} \int_{T_{c}}^{T_{h}} Z T d T
\end{aligned}
$$

Phase and microstructure characterization. The phase structure was investigated by powder X-ray diffraction (XRD) adopting a D/MAX2200pc system (Rigaku, Japan) with $\mathrm{Cu} \mathrm{K \alpha}$ at $40 \mathrm{kV}$ and $40 \mathrm{~mA}$ at $2 \theta=20-80^{\circ}$. The scanning speed and step size were $6^{\circ} \min ^{-1}$ and $0.02^{\circ}$ respectively. The JSM-7900F type scanning electron microscope (SEM) provided with an energy dispersive X-ray spectroscopy (EDX) detector was used to characterize the micromorphology and element distribution.

Theoretical calculations. First-principle calculations based on density functional theory (DFT) was conducted by using projector-augmented wave (PAW) method $^{3}$ as implemented in the Vienna Ab-initio Simulation Package (VASP). ${ }^{4}$ The exchange-correlation energy was calculated based on the Perdew-Burke-Ernzerhof (PBE) function. The electronic wave functions were expanded in plane-waves basis with a cutoff energy $450 \mathrm{eV}$. A $3 \times 3 \times 3\left(\mathrm{~Pb}_{27} \mathrm{~S}_{27}\right)$ supercell was constructed to describing the $\mathrm{Ni}\left(\mathrm{Pb}_{26} \mathrm{NiS}_{27}\right)$ and $\mathrm{Zn}\left(\mathrm{Pb}_{26} \mathrm{ZnS}_{27}\right)$ added systems. The internal coordinates of atoms were optimized until the maximum residual force between atoms is less than $0.01 \mathrm{eV} \AA^{-1}$ and the convergence criteria of total energy was set to $10^{-7} \mathrm{eV}$. Considering that the symmetry broken from the substitution leads to a folding of electronic band structure, the unfolding process was conducted by using band up code..$^{5,6}$ 
2. The thermoelectric transport properties of n-type $\mathrm{PbS}$ by adding $\mathrm{Ni}$ atoms
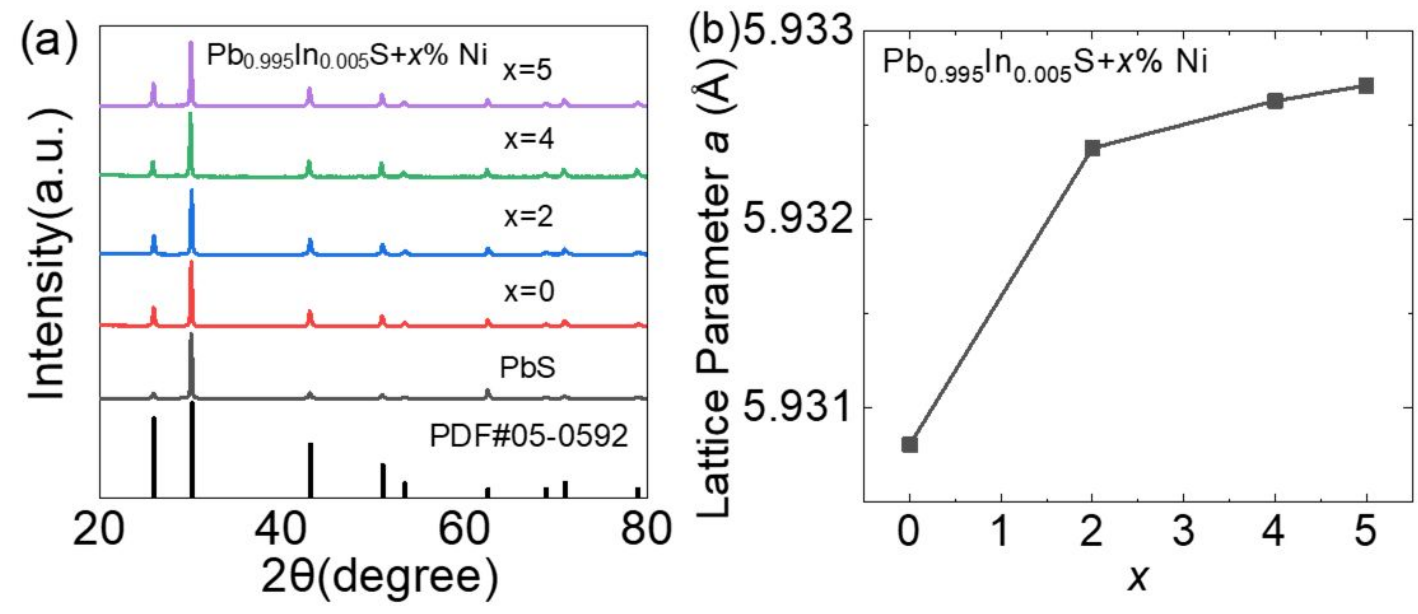

Figure S1. (a) Powder XRD patterns of $\mathrm{Pb}_{0.995} \mathrm{In}_{0.005} \mathrm{~S}+\mathrm{x} \% \mathrm{Ni}(\mathrm{x}=0,2,4,5)$ and (b) the lattice parameters as a function of $\mathrm{Ni}$ fractions. 


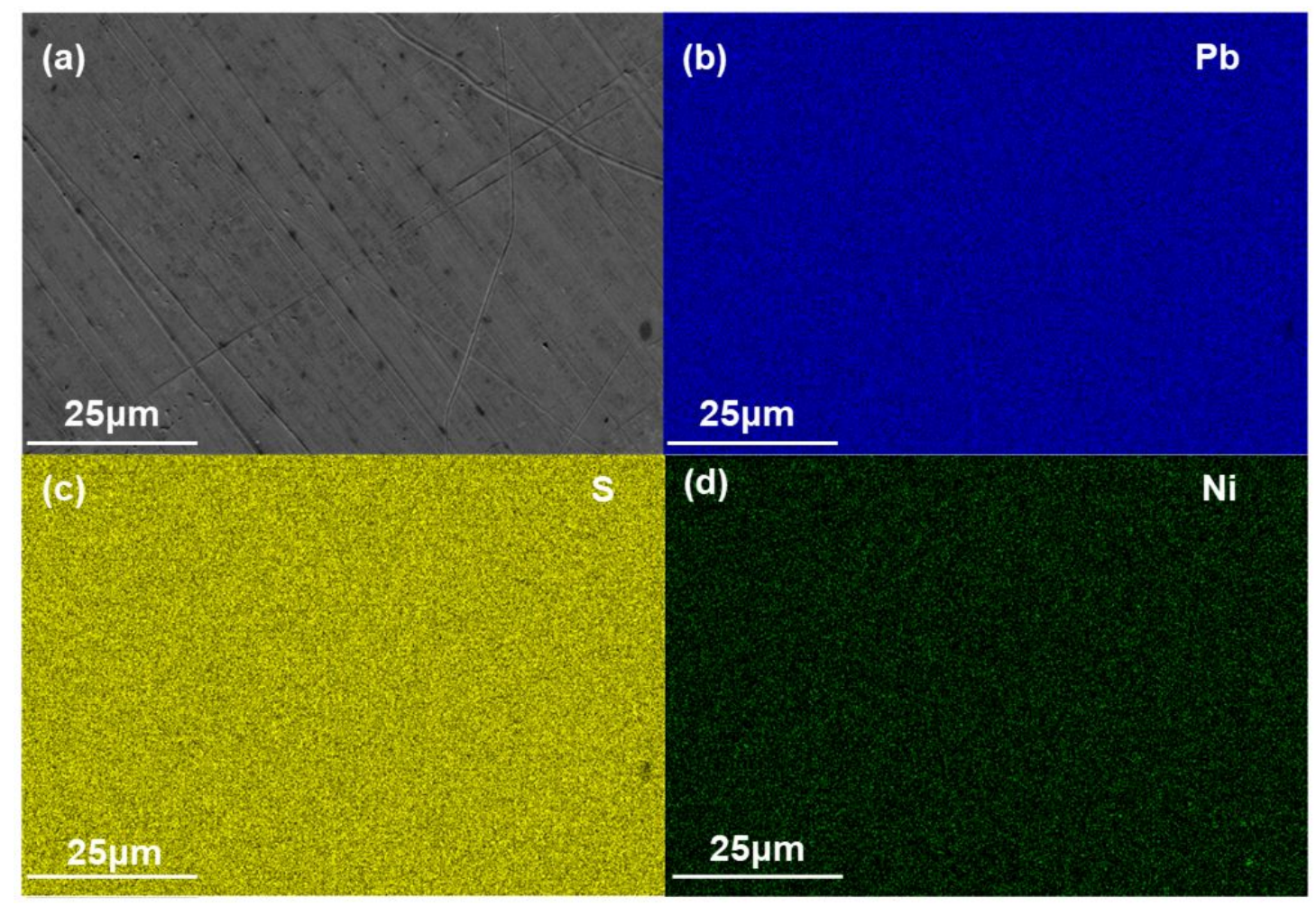

Figure S2. (a) SEM image of $\mathrm{Pb}_{0.995} \mathrm{In}_{0.005} \mathrm{~S}+5 \% \mathrm{Ni}$, the corresponding element distributions are (b) $\mathrm{Pb}$, (c) $\mathrm{S}$ and (d) $\mathrm{Ni}$, respectively. 

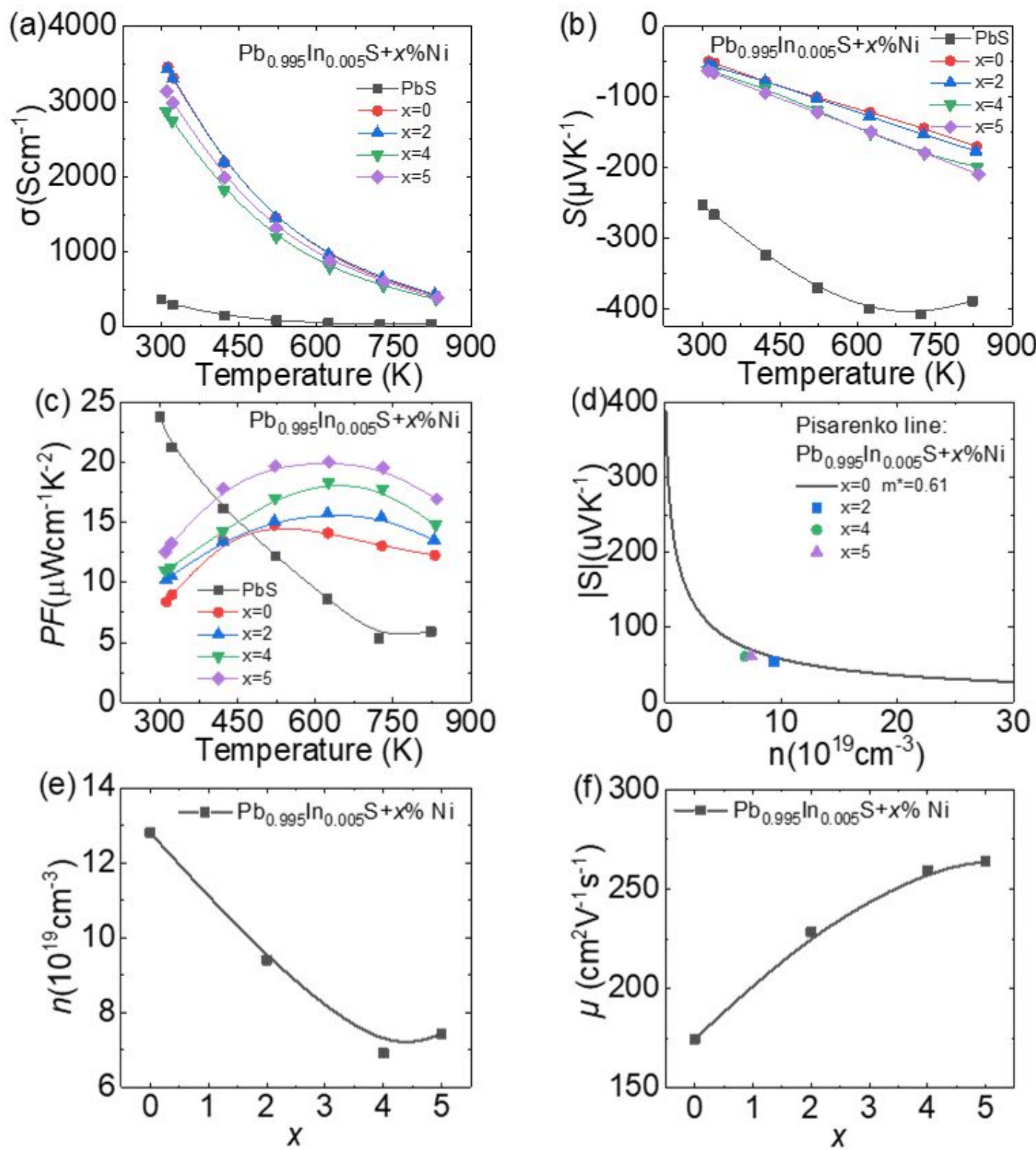

Figure S3. Temperature dependence of electrical transport properties of $\mathrm{Pb}_{0.995} \mathrm{In}_{0.005} \mathrm{~S}+\mathrm{x} \% \mathrm{Ni}$ $(\mathrm{x}=0,2,4,5)$ : (a) Electrical conductivity; (b) Seebeck coefficients; (c) Power factor; (d) Pisarenko plot at room temperature, (e) Carrier concentration and (f) Carrier mobility as a function of Ni fractions. 

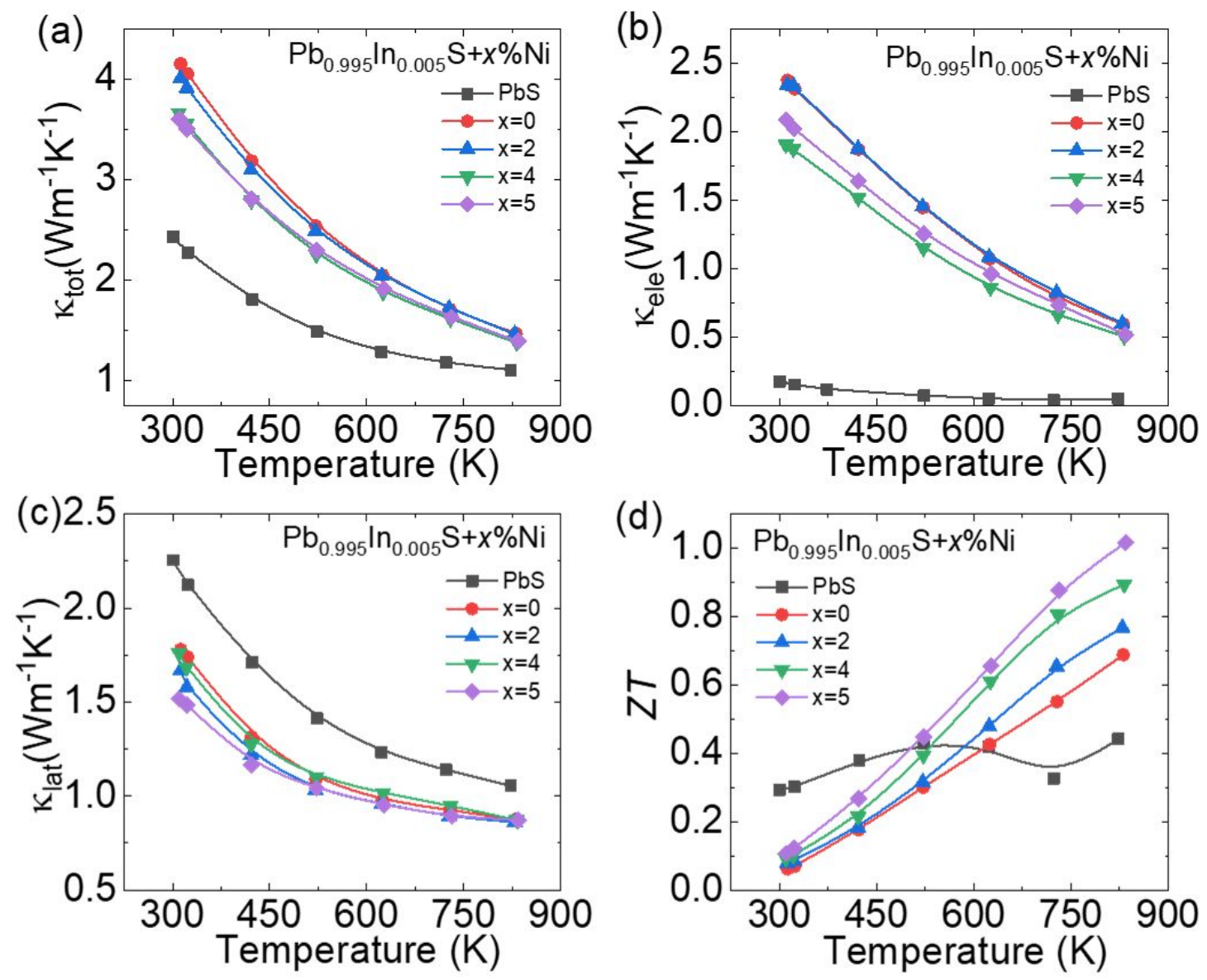

Figure S4. Temperature dependent thermoelectric transport properties of $\mathrm{Pb}_{0.995} \mathrm{In}_{0.005} \mathrm{~S}+\mathrm{x} \%$ Ni ( $x=0,2,4,5)$ : (a) Total thermal conductivity; (b) Electronic thermal conductivity; (c) Lattice thermal conductivity; (d) Dimensionless figure of merit, $Z T$. 


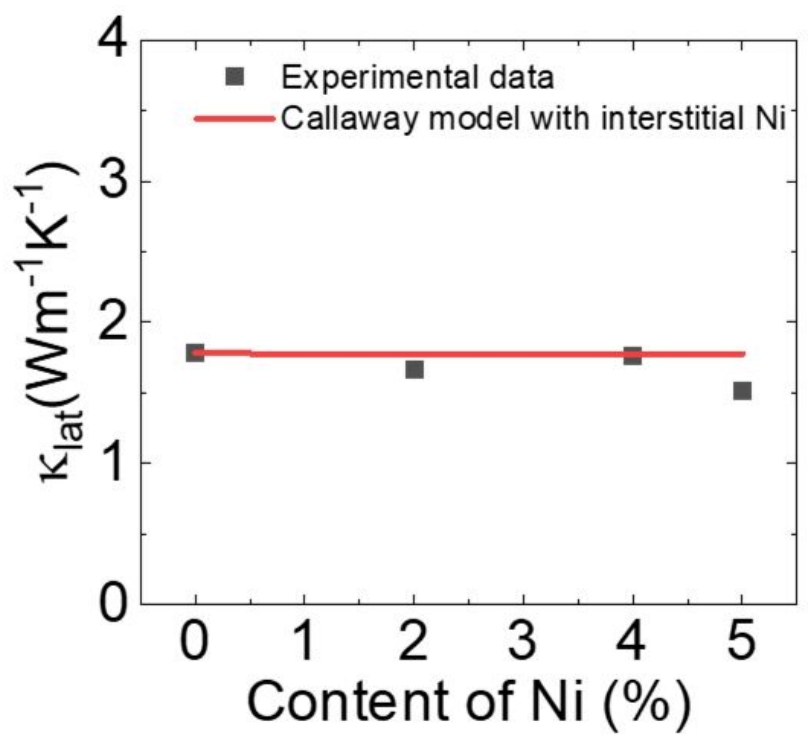

Figure S5. Comparisons of $\kappa_{\text {lat }}$ between experimental and calculated values in Ni-contained samples at $300 \mathrm{~K}$. 

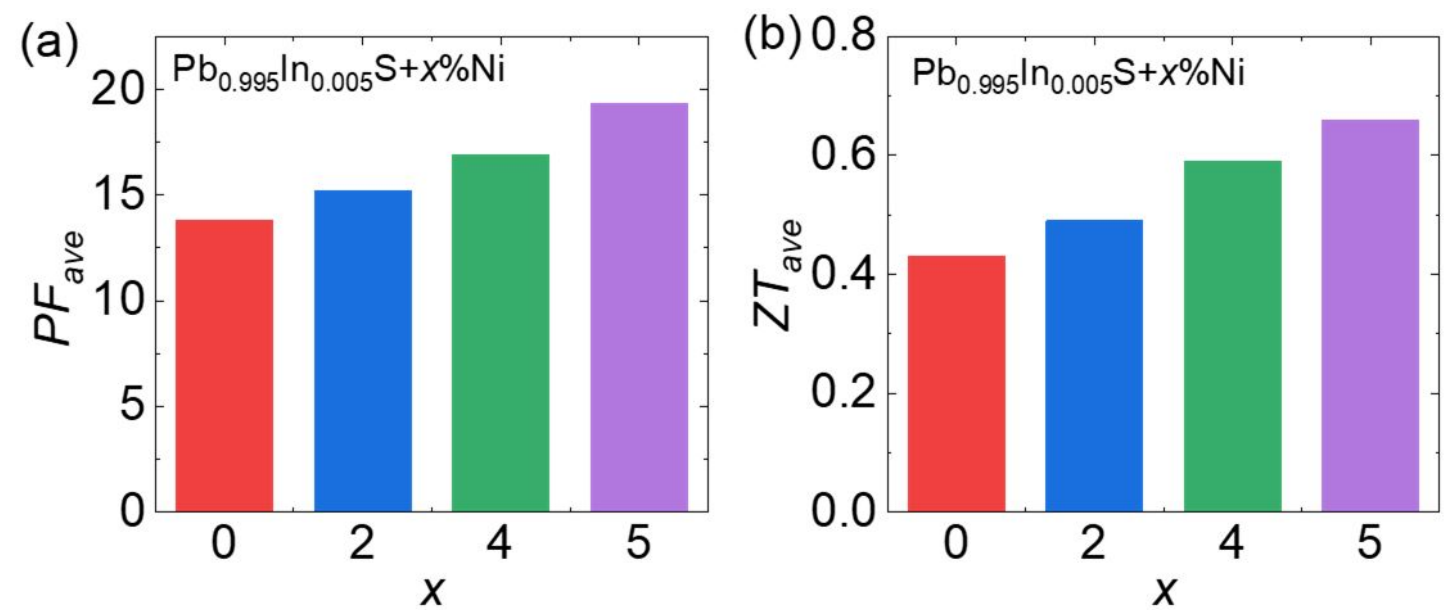

Figure S6. Comparisons of average $P F(\mathrm{a})$ and average $Z T(\mathrm{~b})$ of $\mathrm{Pb}_{0.995} \mathrm{In}_{0.005} \mathrm{~S}+\mathrm{x} \% \mathrm{Ni}(\mathrm{x}=0$, 2, 4, 5) between $423 \mathrm{~K}-823 \mathrm{~K}$. 
3. The thermoelectric transport properties of $n$-type $\mathrm{PbS}$ by adding $\mathrm{Zn}$ atoms
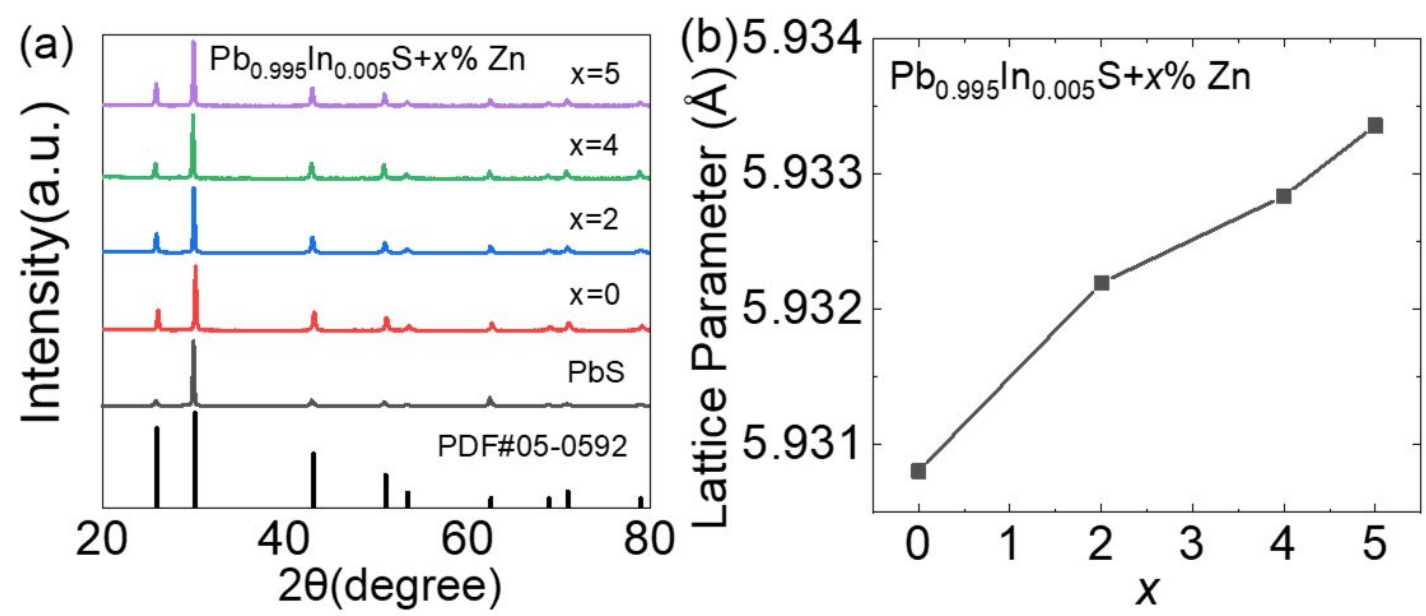

Figure S7. (a) Powder XRD patterns of $\mathrm{Pb}_{0.995} \mathrm{In}_{0.005} \mathrm{~S}+\mathrm{x} \% \mathrm{Zn}(\mathrm{x}=0,2,4,5)$ and (b) lattice parameters as a function of $\mathrm{Zn}$ fractions. 


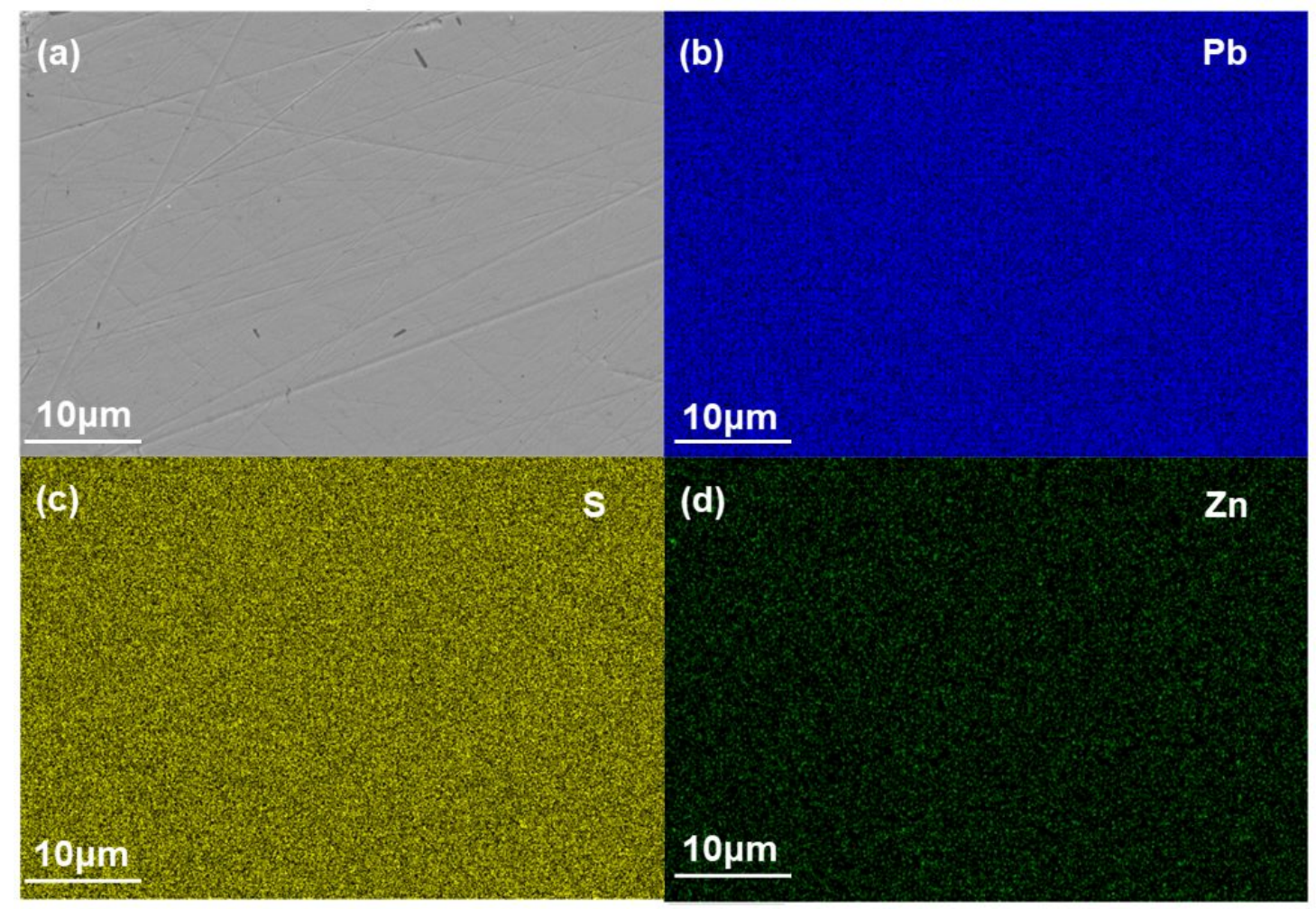

Figure S8. (a) SEM image of $\mathrm{Pb}_{0.995} \mathrm{In}_{0.005} \mathrm{~S}+5 \% \mathrm{Zn}$, the corresponding element distributions are (b) $\mathrm{Pb}$, (c) $\mathrm{S}$ and (d) $\mathrm{Zn}$, respectively. 

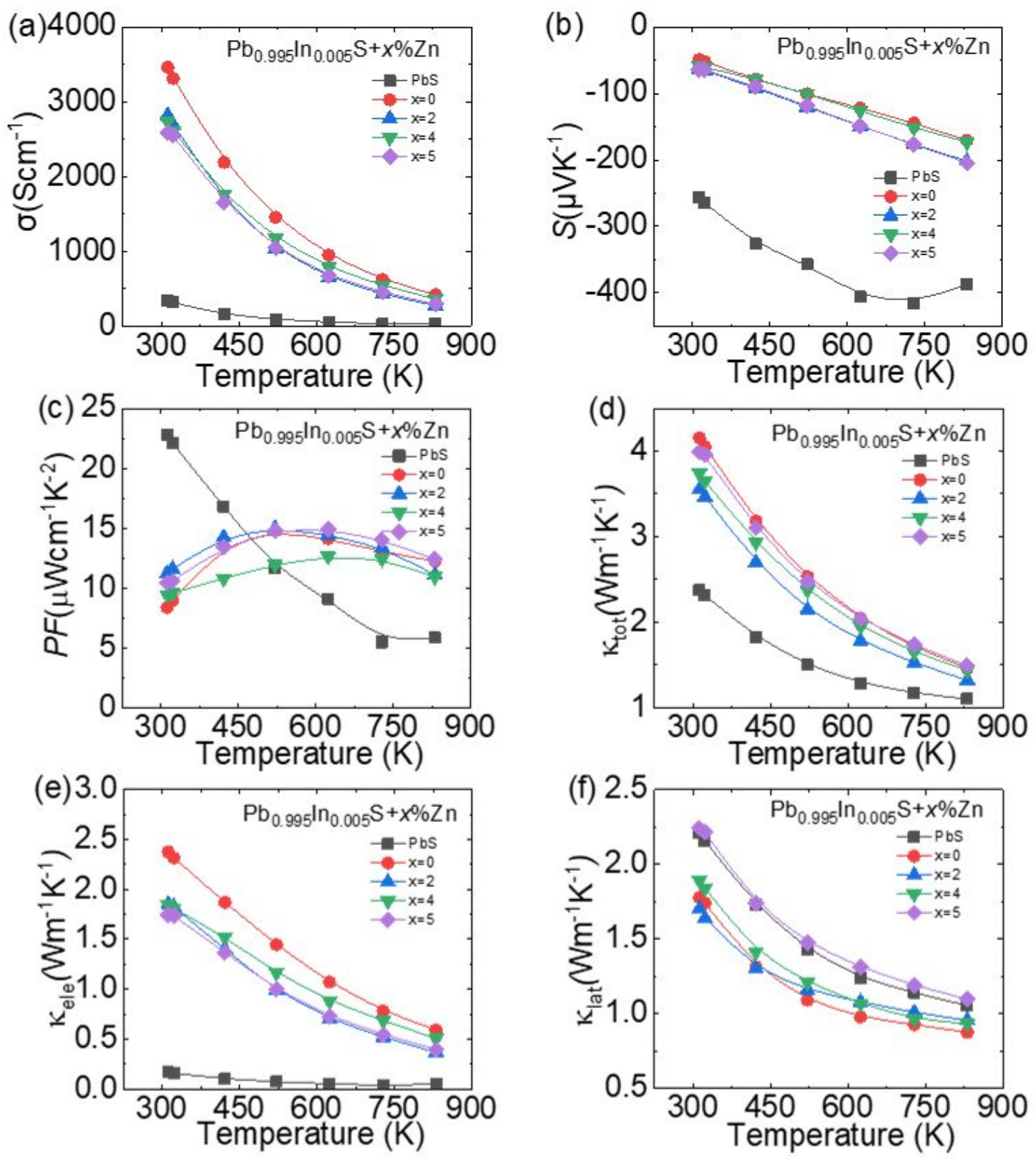

Figure S9. Temperature dependent of thermoelectric transport properties of $\mathrm{Pb}_{0.995} \mathrm{In}_{0.005} \mathrm{~S}+\mathrm{x} \%$ Zn (x = 0, 2, 4, 5): (a) Electrical conductivity; (b) Seebeck coefficients; (c) Power factor; (d) Total thermal conductivity; (e) Electronic thermal conductivity, and (f) Lattice thermal conductivity. 

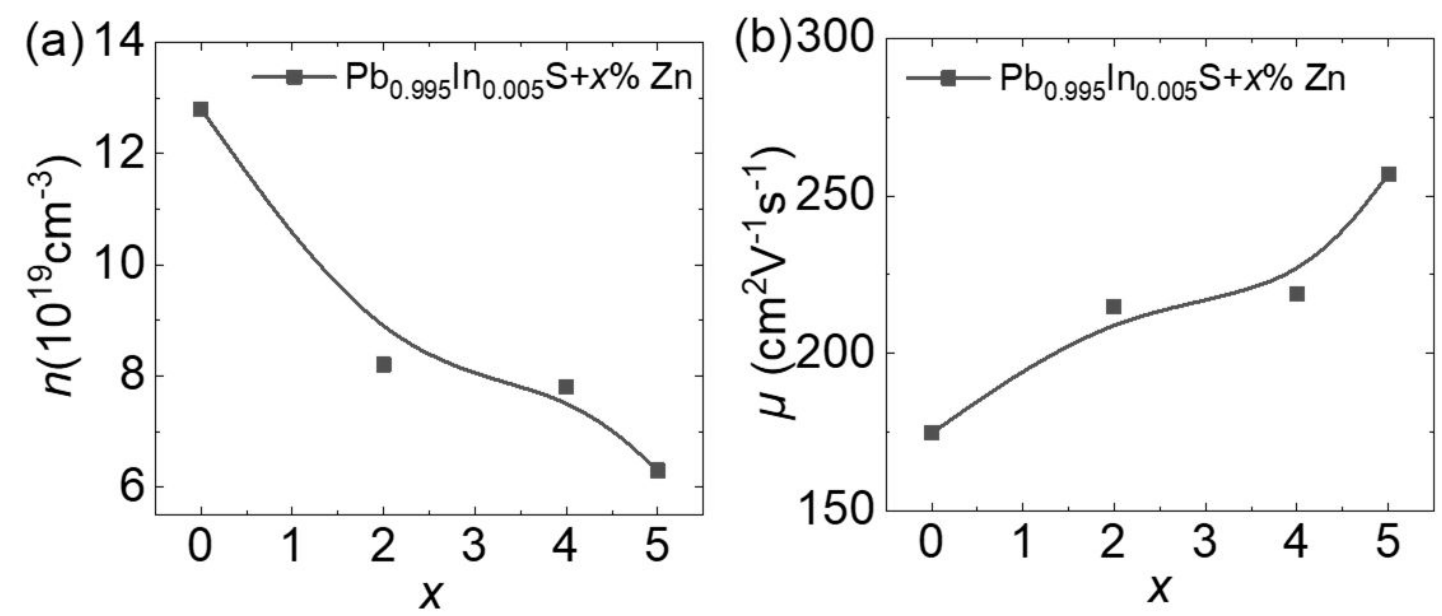

Figure S10. Room temperature (a) Carrier concentration and (b) Carrier mobility as a function of $\mathrm{Zn}$ factions in $\mathrm{Pb}_{0.995} \mathrm{In}_{0.005} \mathrm{~S}+\mathrm{x} \% \mathrm{Zn}(\mathrm{x}=0,2,4,5)$. 


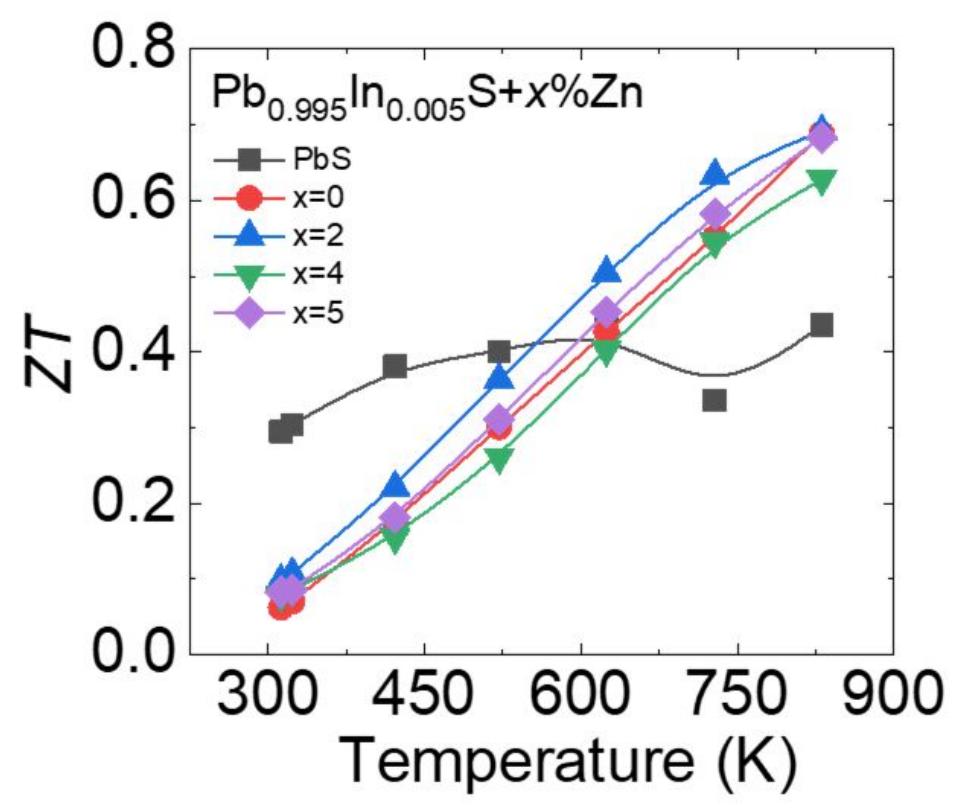

Figure S11. Temperature dependent of the final $Z T$ of $\mathrm{Pb}_{0.995} \mathrm{In}_{0.005} \mathrm{~S}+\mathrm{x} \% \mathrm{Zn}(\mathrm{x}=0,2,4,5)$.

\section{References}

(1) Qin, B. C.; Wang, D. Y.; He, W. K.; Zhang, Y.; Wu, H. J.; Pennycook, S. J.; Zhao, L.-D. Realizing high thermoelectric performance in $p$-type SnSe through crystal structure modification. J. Am. Chem. Soc. 2019, 141(2), 1141-1149.

(2) Otsuka, M.; Homma, R.; Hasegawa, Y. Estimation of phonon and carrier thermal conductivities for bulk thermoelectric materials using transport properties. J. Electron. Mater. 2017, 46(5), 2752-2764.

(3) Blochl, P. E. Projector augmented-wave method. Phys Rev B Condens Matter 1994, 50(24), 17953-17979.

(4) Kresse; Furthmuller. Efficient iterative schemes for ab initio total-energy calculations using a plane-wave basis set. Physical review. B, Condensed matter 1996, 54(16), 11169-11186.

(5) Medeiros, P. V. C.; Stafstrom, S.; Bjork, J. Effects of extrinsic and intrinsic perturbations on the electronic structure of graphene: Retaining an effective primitive cell band structure by band unfolding. Physical Review B 2014, 89(4), 4.

(6) Medeiros, P. V. C.; Tsirkin, S. S.; Stafstrom, S.; Bjork, J. Unfolding spinor wave functions and expectation values of general operators: Introducing the unfolding-density operator. Physical Review B 2015, 91(4), 5. 